\title{
Evaluation of Job Preference of Prospective Dentists using Discrete Choice Experiment
}

\author{
Dr. Rabindra Man Shrestha, BDS, $M D S^{1}$ \\ Dr. Sujita Shrestha, BDS, $M P H^{2}$ \\ Vishnu Prasad Sapkota
}

\begin{abstract}
Introduction: The number of dentists is increasing in Nepal and they have a tendency to accumulate in the capital and major cities of the country. Moreover, their job priorities and professional inclinations have not been identified yet. The need, demand and supply of the dental professionals and their retention in rural areas are required to be studied from the health economics perspective. The main objective of the study was to identify preferences on job characteristics of prospective dentists and determine monetary valuation of the attributes of job choices.
\end{abstract}

Methodology: Discrete choice experiment (DCE) with choice sets in the form of selfadministered questionnaire was used. 402 Nepalese dental students, interns and recently graduated dentists from various universities were studied. Seven job characteristics and their corresponding levels were determined from focus group discussion. We adopted main effect fractional factorial design to create 48 choice sets. The respondents were divided into 6 blocks, with each block comprising of 8 choice sets. Each choice set comprised of two choices and an alternative specific constant (ASC). Multiple logistic regression with mixed logit model was applied to analyze the preferences of various job characteristics.

Results: The response rate was $74 \%$. Further educational opportunity was the most important job attribute for dentists in choosing their job. The order of preference for other job characteristics was: amenities at workplace, distance to workplace, private practice opportunity, and additional incentive. $(p<0.01)$. Whereas, the job attribute CPD opportunity was not found statistically significant and has negative estimated coefficient. The 'willingness-to-accept' was found maximum (NRs. 144,000) for educational opportunity. ( $p / a)$. The preferences varied with gender, location and respondent category.

1 Dr. Shrestha is Associate Professor (Principal Investigator) of Kantipur Dental College, KU. Email: rabindraortho@gmail.com

2 Dr. Shrestha is Lecturer (Co-investigator) (PhD Scholar) of Kantipur Dental College, KU

3 Mr. Sapkota is Co-investigator of Institute for Nepal Environment and Health System Development (INEHD) Shantinagar, Kathmandu 
Conclusion: Job characteristics like further education opportunity and amenities at workplace should be given importance in creating job opportunities for dentists. The offering of preferred job attributes could be helpful in retaining the dental professionals in rural areas.

Keywords: dentist, discrete choice experiment, job attribute, willingness to accept

\section{INTRODUCTION}

Dental health assumes important role in the attainment of health and wellbeing of the individual. In recent decades, dental health service and dental education have been developed remarkably in Nepal. Until the year 2004, dentists used to graduate from foreign countries however, presently there are 12 dental colleges and six postgraduate dental institutions in Nepal. There are presently 1800 dentists and 300 dental specialists in Nepal (NMC, 2013). At present, five dental colleges are producing Bachelors in Dental Surgery (BDS) graduates; and about 200-250 dentists are produced every year from the country and abroad (Dixit, 2009). If the current trend continues, the country will be producing 500-600 dentists per annum in 2016/17.

Dental health service is provided in various government and non-government health institutions including government hospitals, private hospitals/clinics, dental/medical college teaching hospitals, military/police hospitals, and health centers operated by NGO's. Private health sectors play a major role in employing dentists. According to a report, $42.8 \%$ dentists are working in private clinic/hospital, and $31.4 \%$ are working in dental/medical college hospitals. The same report has revealed that the government health service recruits $8.7 \%$ (including permanent and contract), and military and police health service recruit 3.3\% dentists (Shrestha, 2008, Shrestha, 2015).

State dental health service is governed by Oral Health Focal Point, Health Services Department. The government dental health service is limited to zonal hospitals and few district hospitals only. Nepal government has the strategic plan to offer dental service in all district hospitals. In 2004, oral health policy was formulated and oral health service was provided as a component of essential health care service package (National Oral Health Policy-Nepal, 2014, NHSP-II 2010).

Effective health care service demands adequate number of human resource with proper allocation and management. According to World Health Organization (WHO), 23 health professionals are required per ten thousand populations to achieve the Millennium Development Goal (WHO, 2006). Similarly, World Dental Federation (FDI) has recommended one dentist per 5000 population (Colombet, 1996). In Nepal, 30 districts do not possess any dentists and 25 districts possess only 1-3 dentists per 
district. There is acute shortage of dentists in mid-western and far-western regions of Nepal; and more than $55 \%$ of dentists reside in Kathmandu valley (Shrestha, 2015).

The number of dental graduates is increasing; however there is tendency to accumulate the professionals in capital and urban cities. Proper job allocation and distribution have not been suitably planned in Nepal. The concerned authorities have not allocated dentists in the rural areas, nor do they have strategic plan to retain them in remote areas. The information on human resource situation and service distribution of the dentists is scarce. Appropriate dentist-population ratio is one of the major indicators of any state health service.

Human resource management with proper allocation of dental health professionals is essential for effective health service delivery. The dental health service should also be viewed from health economics perspective for sustainable professional development. The health professional's priority and job preferences need to be evaluated for effective creation of job opportunities and retention of the professionals in specific job areas. The gap between demand, need and supply components in dental health sector should be assessed through health economics research. The present study thus attempts to identify the perspective of dentists about professional preferences using Discrete Choice Experiment (DCE).

The Discrete Choice Experiment is the most appropriate and recent model used in health sector. It has been formulated and recommended by WHO for studies on workforce recruitment and retention in health (WHO, 2012). DCE is a quantitative method for valuing different factors that influence job choices. It provides quantitative information on the relative importance of various job characteristics that influence the job choices of health professionals, as well as the trade-offs between these factors and the probability of take-up of defined jobs.

\section{LITERATURE REVIEW}

Very few studies have been conducted on Nepalese dentists' perspective on job inclinations and career. One such questionnaire-based study among graduating Nepalese BDS students showed that the career option was $75 \%$ in dental sciences and $12.5 \%$ in basic medical sciences for post graduate studies. Subject of choice among clinical dental subjects were Orthodontics and Prosthodontics, followed by Conservative dentistry and endodontics (Poudel, 2014). Sapkota and Amatya (2013) studied the intended location of future career practice of graduating Nepalese medical students, based on social cognitive career theory. According to the study, $66 \%$ medical students and interns opt to practice within the country, while rest choose to go abroad. Similarly, the same study showed $50.8 \%$ respondents like to practice in rural areas 
while $49.2 \%$ like to practice in cities, and $82 \%$ opt to work in public sector while only $18 \%$ like to work with private sector.

Discrete choice experiment approach has been used in very few studies related to dental health service. Santos et al. (2013) studied Brazilian dental students' perceptions and motivations towards professional career. Most students especially female and low-income students intended to become specialists and work in both the public and private sectors simultaneously. The study suggested combining the job opportunity in private and public dental practice to achieve better income and job security.

An oral health project assessed Australian dental practitioners' attitude and barrier towards living and working in rural areas. Policy interventions to attract health professionals to rural locations were: selection of students into health schools, exposure to rural practice through education programs, locating educational institutions in rural areas, and coercion through bonding, incentives and support. The report provided the policy relevant findings on recruitment and retention of rural dental practitioners and suggested DCE approach to provide evidence for health care decision making (Crocombe, 2012).

The systematic review indicated that DCE have been applied to a wide number of areas in health science and a number of methodological issues have been addressed. Ryan et al. (2001) utilized DCE for eliciting preferences in the delivery of health care among outpatients. Patients were questioned about service attributes: staff seen (junior doctor or specialist), waiting time, continuity of contact with same staff, provision of a phone-in/advice service,length of consultation, and change in pain levels. The value of attributes was estimated in terms of time, and this was converted to a monetary measure using the value of waiting time for public transport.

Ubach et al. (2003) assessed Scottish hospital consultants' preference for job characteristics using DCE. They analyzed monetary valuations of job characteristic based on consultants' willingness to pay and willingness to accept extra income for a change in each job characteristic. This study reported that among all, 'being on call' was the most important attribute, as consultants would need to be compensated up to $£ 18000$ (30\% of income) for a high on-call workload. Compensation of up to $£ 9700$ (16\% of income) would be required to 'miss opportunities to undertake non-NHS work'. Consultants would be willing to accept $£ 7000$ (12\% of income) in compensation for fair rather than good working relationships with staff, and $£ 6500$ (11\% of income) to compensate them for a shortage of staff. 
Koopmanschap et al. (2010) assessed decision makers' choice in healthcare priority setting using DCE among Dutch healthcare professionals. According to the study, severity of disease, costs per quality-adjusted life-year gained, individual health gain, and the budget impact were the most decisive decision criteria. A program targeting more severe diseases increased the probability of reimbursement dramatically. Respondents preferred health gains that include quality of life improvements over extension of life without improved quality of life.

Gallego et al. (2015)studied the relative job preferences and retention of allied health professionals living in rural area and working with disabled patients in Australia. The preferences were explored using a best-worst scaling discrete choice experiment (BWSDCE). For this group, 'high autonomy of practice' was the most valued attribute, followed by 'travel one or less nights away per month', 'travel two or three nights away per month' and 'adequate access to professional development'. Preferences differed according to age, marital status and having dependent children.

Available literature indicate that DCE have been common in identifying factors for job choices However, given the scarcity of medical professional such as dentists in the rural areas, identifying the factors determining job choice among dentists in the context of Nepal would be useful for designing incentives packages by the government. In this regards, the objectives of this paper are identify preferences of Nepalese prospective dentists on various job characteristics and determine monetary valuation of attributes of job choices in terms of willingness to accept.

\section{METHODOLOGY}

Evaluation of prospective dentists' job preference was done by using discrete choice experiment (DCE). The method was experimental, cross-sectional and non-interventional quantitative approach. Discrete Choice Experiment (DCE) is a quantitative method where a decision-maker is asked to choose one alternative from a set of options (called choice set); these alternatives are defined by specific characteristics called attributes. From this, a researcher can evaluate relative importance of various attributes that influence decision-makers' choice behaviour (Louviere et al., 2000).

This technique has its origin from probabilistic choice theory and the economic theory of demand (Random Utility Theory) and is based on the work of Lancaster, who proposed that the demand for good was effectively the demand for specific combination of product characteristics or attributes (Lancaster, 1966). While undergoing the choice decision, neo-classical economic theory assumes that the decision-maker has perfect discriminatory power and unlimited information processing capacity, therefore, can rank the set of options in well-defined and consistent manner. The decision-maker 
can thus determine his/her best choice and will repeat this choice under identical circumstances (Anderson et al, 1992).

According to Random Utility theory (RUT), it is assumed that the decision-maker chooses the alternative that maximizes the total utility $\left(\mathrm{U}_{\mathrm{j}}\right)$. It can be represented algebraically as:

$\mathrm{Uj}=\mathrm{Vj}+\varepsilon_{\mathrm{j}}$

The researcher however cannot observe individual's true utility function and hence cannot determine total utility deterministically. Therefore, total utility can be fragmented into the part of utility function $\left(\mathrm{V}_{\mathrm{j}}\right)$ that the researcher can observe and the part that he/she cannot observe $\left(\varepsilon_{\mathrm{j}}\right)$. The part of utility $\left(\mathrm{V}_{\mathrm{j}}\right)$ is considered to be the function of alternative specific and individual characteristic. Researcher does not have information about $\left(\varepsilon_{\mathrm{j}}\right)$. So, he/she considers this part as a random component, and uses probabilistic choice theory for estimation of parameters that provide information about relative importance of the different attributes that influence decision-makers' choice behaviour. Type of probabilistic choice model researcher applies depends upon assumptions about the random parameter $\left(\varepsilon_{j}\right)$ (Train, 2003).

In this study, we adapted mixed logit model which required that model should be adapted as random parameter specification.

$\mathrm{U}_{\mathrm{jn}}=\beta_{\mathrm{o}}+\beta_{\mathrm{ln}} \times \mathrm{X}_{\mathrm{ljn}}+\cdots+\beta_{\mathrm{mn}} \times \mathrm{X}_{\mathrm{mjn}}+\varepsilon_{\mathrm{jn}}$

The $X_{m}$ indicates job attributes used in the analysis, $\beta_{m n}$ indicates marginal utility for each attribute. In the above equation, coefficient also include n subscript which means that coefficients vary with individual respondents as well. This specification is called random parameter mixed logit model. This method was estimated using maximum likelihood methodology. The coefficients $(\beta)$ are used in the analysis of: Which attributes are more important and how important is one attribute in comparison to other? How individuals trade between attributes of a job, that is, how much of one attribute they are willing to give up for the improvements in another? How much salary an individual would be willing to give up for improvements in other attributes of a job

In health care sector, this methodology is applied with two assumptions. Firstly, healthcare interventions, services, or policies can be described by their characteristics (or attributes) and secondly, an individual's valuation depends on the levels of these characteristics. This method is, therefore, gaining popularity in health policy and 
health service research areas because policy makers can explicitly identify the choice and preferences of individuals and patients on alternative courses of policy actions. It makes investment decisions of scarce health care resources more evidence based and welfare enhancing.

The designing of DCE requires specific procedure, and it is discussed according to the design stages proposed by Ryan and Gerard (2003). This procedure has mostly been used in the literature of health economics (Kjær, 2005).

\section{Stages in Discrete Choice Experiment}

Stage I: Selection of attributes and assignment of levels

The first stage in constructing a DCE was to identify the attributes of the job and levels of attributes that are important to the dental professionals and policy makers. Study attributes and their levels were identified based on literature search. A series of job attributes were collected from the published literature and policy documents.

A workshop was then organized among key informants including professional dentists, those involved in academia, and dental students to identify the suitable attributes. This step also reflected various job attributes that are important in terms of dentists' career and policy.

Third step involved a focus group discussion among the professional dentists, research team and policy makers. At the end, the researchers came-up with the attributes of the job and their levels that would influence individuals' decision to take up the job as a dentists and policy relevant to dental health.

After undergoing those steps, seven attributes were finalized. Educational opportunity was considered one of the important features in dentists' jobs. Many health institutions and dental colleges provide academic opportunity after completion of specified job duration; and eventually after post-graduation the employee dentists are coerced through bond. Young respondents considered physical amenities and additional incentives at job as one of the important determining features for the job intake. Training and continuous professional development opportunities were thought to be important human resource development strategies in medical sector. Distance to the workplace particularly far from the home town was also highly emphasized in the discussion. In many cases, policy makers are looking for optimum incentives to recruit the professionals far from their regular residential area. Finally salary was included as important attribute with continuous level of variables. 
After identifying the attributes, next stage was to determine the levels of attributes. In our study, all the attributes were defined with two levels, except for job attribute 'salary', which was considered as continuous variable and defined in six levels. Levels were consistent with practical importance and actionable from the policy perspective. The monthly salary levels were determined as per the present market value. Finally we decided to design the choice tasks as unlabelled design, which include two job profiles. Dentists' job attributes and their levels are summarised in Table 1.

\section{Table 1:Dentists' Job Attributes and Their Levels}

\begin{tabular}{ll}
\hline Attributes & Levels \\
\hline Educational opportunity & Yes \\
& No \\
Amenities at workplace & Basic amenities \\
& Modern Amenities \\
Additional incentives & Yes \\
& No \\
Distance to workplace & Nearby home \\
& Far away from home \\
Continuous Professional & Less \\
Development (CPD) opportunity & More \\
Private practice opportunity & Yes \\
& No \\
Salary (per month in NRs) & $15,000,25,000,35,000,45,000,55,000,65,000$ \\
\hline
\end{tabular}

Stage 2: Selection of experimental design

Having established the relevant attributes and their levels, hypothetical job choices with different combinations of attributes and levels were constructed. In this stage, the attributes were combined according to their levels into unique choice sets as per the experimental design principles. As discussed in above stage, six attributes had two levels, and one attribute had 6 levels. Therefore, a full factorial design required $\left(2^{6} \times 6^{1}\right)=384$ alternatives to be presented to the respondents which seemed to be quite unrealistic and cumbersome. Therefore, it was necessary to reduce the number of alternatives and create a choice experiment that keeps the choice task simple to the respondents and able to extract all the necessary information from the choices. For this purpose, a fractional factorial design was proposed which considers a sub-set of alternatives from original full factorial design in such a way that properties of full factorial design are maintained and main effects are estimated as efficiently as possible. 
This kind of study design is called 'main effect fractional factorial design'. In this study, LMA design was adapted which directly creates a CE design from the orthogonal main-effect array, and ensured desirable characteristics for an experimental design. This experimental design was implemented in $\mathrm{R}$ statistical software using 'Support CEs' package. The program was used to reduce 384 alternatives to 96 alternatives or 48 statistically efficient choice sets. As each respondent was presented with eight choice sets, respondents were divided into 6 blocks. There were eight different choice sets in each block with two choices and respondents could also opt not to choose any given choices i.e. alternative specific constant (ASC).

Stage 3: Development of the questionnaire, pretesting, and data collection

Finally, the choice sets were incorporated into questionnaire format with 'Job A', 'Job $\mathrm{B}^{\prime}$ and 'None of them' options. The questionnaire also comprised of consent from and information to the respondents regarding purpose of the study and explanations about the job attributes.

Our interest was to investigate how preferences differ according to the characteristics of respondents. So, information on background characteristics, such as sex, age, ethnicity, place of origin (district), study category (scholarship, self-finance), university attended (TU, KU, BPKIHS, foreign) were also included in the questionnaire.

We conducted pre-test of the survey tool for the validity and reliability of data. In the pretesting, we included 36 respondents i.e. one tenth of the total sample size. Pilot testing was done to determine whether respondents understood the descriptions of attributes and levels, whether they could cope with the number of attributes and number of choices; and whether they understood the choices. The pilot size was of sufficient sample size to do econometric analysis on the data to test the coefficients. The coefficients were moving in the expected direction. The questionnaire was modified according to the feedback of the pretesting.

The sample was purposive and sample size was determined as 360 (McFadden, 1984) based on total number of dentists in the country. The subjects for the study were final year BDS students, interns and dentists with temporary registration (within two years of passing BDS). The study sites were dental colleges, viz People's Dental College Kathmandu, Universal College of Medical Sciences Bhairahawa affiliated to Tribhuvan University, Kantipur Dental College Kathmandu affiliated to Kathmandu University, B. P. Koirala Institute of Health Sciences Dharan and various private and government hospitals. 
The data were collected using a self-administered structured questionnaire. The research was done after getting ethical approved from Nepal Health Research Council.

\section{Stage 4: Data input and analysis}

Data entry was performed in SPSS Version 20. The data-base was later imported to $\mathrm{R}$ statistical program. The mlogit package was used for the analysis. Job preferences were compared among various characteristics like gender, study category, university attended, geographic locations etc. Multiple logistic regression with mixed logit analysis was done to analyze the correlation between various characteristics. Eventually, monetary valuation of attributes i.e. willingness to pay and willingness to accept was analyzed.

\section{RESULTS}

The questionnaires were distributed to 550 subjects; however 407 respondents reported, i.e. the response rate was $74 \%$. A total of 402 questionnaires were used for analysis which fulfilled the completeness of data. The sample comprised of 117 male and 285 female with the mean age of 24.78 (SD 1.98) years. The age ranged from 21 to 32 years.

The analyzed sample included 134 dentists, 118 interns and 150 final year dental students. Among the total respondents, 360 studied under self-finance and 42 obtained scholarship. Based on the university, 214 were from Tribhuvan University, 84 from Kathmandu University, 62 from BPKIHS and 42 from foreign universities. Out of all, 140 were from the Kathmandu valley and 262 were from outside the Kathmandu valley.

Each respondent was provided with a block of questionnaire comprising of eight different job choice sets; each choice set comprised of Job A, Job B and 'none of them' options. Out of all completely filled choice sets, 1475 choices were made for Job A and 1251 for Job B, while 490 choices were for 'none of them'.

The present study shows that respondents have given most preference to 'educational opportunity for post-graduate studies', followed by 'amenities at workplace, 'distance to work place', 'private practice opportunity', and 'additional incentive'. The given attributes are statistically significant at $\mathrm{p}<0.05$ (Table 2). 
Table 2: Job Preference of Various Attributes

\begin{tabular}{lllll}
\hline Variables & Estimate & $\begin{array}{l}\text { Standard } \\
\text { error }\end{array}$ & t-value & p-value \\
\hline Educational opportunity & 0.684 & 0.037 & 18.293 & $0.0001^{* * *}$ \\
Amenities at workplace & 0.202 & 0.032 & 6.265 & $0.0001^{* * *}$ \\
Distance to workplace & 0.194 & 0.033 & 5.945 & $0.0001^{* * *}$ \\
Private practice opportunity & 0.104 & 0.039 & 2.672 & $0.0075^{* *}$ \\
Additional incentives & 0.089 & 0.032 & 2.811 & $0.0049^{* *}$ \\
Salary & 0.0001 & 0.000 & 20.523 & $0.0001^{* * *}$ \\
CPD & -0.002 & 0.034 & -0.062 & 0.9502 \\
ASC & 1.254 & 0.120 & 10.454 & $0.0001^{* * *}$ \\
sd: Educational opportunity & 1.021 & 0.088 & 11.647 & $0.0001^{* * *}$ \\
sd: Private practice opportunity & 0.415 & 0.135 & 3.080 & $0.0021^{* *}$ \\
sd: Distance to workplace & 0.397 & 0.061 & 6.539 & $0.0001^{* * *}$ \\
sd: Additional incentives & 0.199 & 0.098 & 2.026 & $0.0428^{*}$ \\
\hline
\end{tabular}

The coefficient associated with alternative specific constant (ASC) was found in positive value and was statistically significant, which indicates that a significant number of respondents also chose 'none of the given alternatives'. The statistically significant values of standard deviation within the job attributes denote heterogeneity among the respondents' choice sets.

\section{Sub-group analysis}

In the following section, the results have been stratified across the respondents' characteristics. The preferences of job attributes were compared for the respondents' characteristics like sex, study category, university attended and place of origin.

The comparative analysis between male and female respondents showed that both of their most preferred job attribute was 'academic opportunity', while the second most preferred job attribute was 'amenity at job' for male and 'private practice opportunity' for female. For both gender groups, 'CPD opportunity' was least preferred (Table 3).

The comparative analysis of job preference was done between the respondents studied under scholarship and those studied with self-finance. Both categories preferred 'academic opportunity' followed by 'amenity at workplace'. While, scholarship students least preferred 'additional incentive', self-finance students least preferred 'CPD opportunity' (Table 4). 
Table 3: Different Preference between Gender Categories

\begin{tabular}{lllllll}
\hline & \multicolumn{3}{c}{ Male } & \multicolumn{3}{c}{ Female } \\
\cline { 2 - 7 } & Estimate & SE & p-value & Estimate & SE & p-value \\
\hline Academic opportunity & 0.813 & 0.073 & $0.000^{* * *}$ & 0.637 & 0.043 & $0.000^{* * *}$ \\
Amenity at workplace & 0.230 & 0.064 & $0.0003^{* * *}$ & 0.189 & 0.037 & $0.000^{* * *}$ \\
Additional incentives & 0.147 & 0.065 & 0.0236 & 0.079 & 0.037 & $0.031^{*}$ \\
Distance to workplace & 0.216 & 0.064 & $0.0008^{* * *}$ & 0.182 & 0.038 & $0.000^{* * *}$ \\
CPD opportunity & -0.144 & 0.071 & 0.0433 & 0.051 & 0.039 & 0.1986 \\
Private practice opportunity & 0.127 & 0.074 & 0.0839 & 0.192 & 0.059 & $0.0012^{* *}$ \\
Salary & 0.000 & 0.000 & $0.000^{* * *}$ & 0.000 & 0.000 & $0.000^{* * *}$ \\
ASC & 1.928 & 0.237 & $0.000^{* * *}$ & 1.021 & 0.138 & $0.000^{* * *}$ \\
\hline
\end{tabular}

Table 4: Different Preference between Study Categories

\begin{tabular}{lllllll}
\hline & \multicolumn{3}{c}{ Scholarship } & \multicolumn{3}{c}{ Self-finance } \\
& Estimate & SE & p-value & Estimate & SE & p-value \\
\hline Academic opportunity & 0.887 & 0.122 & $0.000^{* * *}$ & 0.680 & 0.040 & $0.000^{* * *}$ \\
Amenity at workplace & 0.304 & 0.107 & $0.0044^{* *}$ & 0.197 & 0.034 & $0.000^{* * *}$ \\
Additional Incentives & -0.017 & 0.110 & 0.8782 & 0.106 & 0.034 & $0.0017^{* *}$ \\
Distance to workplace & 0.225 & 0.107 & 0.0362 & 0.194 & 0.035 & $0.000^{* * *}$ \\
CPD Opportunity & 0.079 & 0.120 & 0.509 & -0.010 & 0.037 & 0.7749 \\
Private practice Oppo & 0.258 & 0.123 & 0.0359 & 0.106 & 0.040 & $0.0087^{* *}$ \\
Salary & 0.000 & 0.000 & $0.000^{* * *}$ & 0.000 & 0.000 & $0.000^{* * *}$ \\
ASC & 2.239 & 0.364 & $0.000^{* * *}$ & 1.175 & 0.128 & $0.000^{* * *}$ \\
\hline
\end{tabular}

While comparing the preference of job choice among the respondents from various universities, the most preferred choice was 'academic opportunity' for all the groups. The second most preferred job choice was found to be 'amenity at work place' for the graduates from BPKIHS, KU and abroad, whereas it was 'private practice opportunity' for TU graduates. (Table 5).

The difference in order of preference of job attributes between respondents residing outside the Kathmandu valley and in the Kathmandu valley is given in Table 6. According to the study, both groups were found to prioritize 'academic opportunity' the most. The second most preferred job attribute for the respondents outside the Kathmandu valley group was 'amenity at workplace'; while it was 'distance to workplace' for those inside the Kathmandu valley. The least preferred choice for the respondents outside Kathmandu valley was 'CPD opportunity', while that it was 'salary' for those inside the Kathmandu valley 


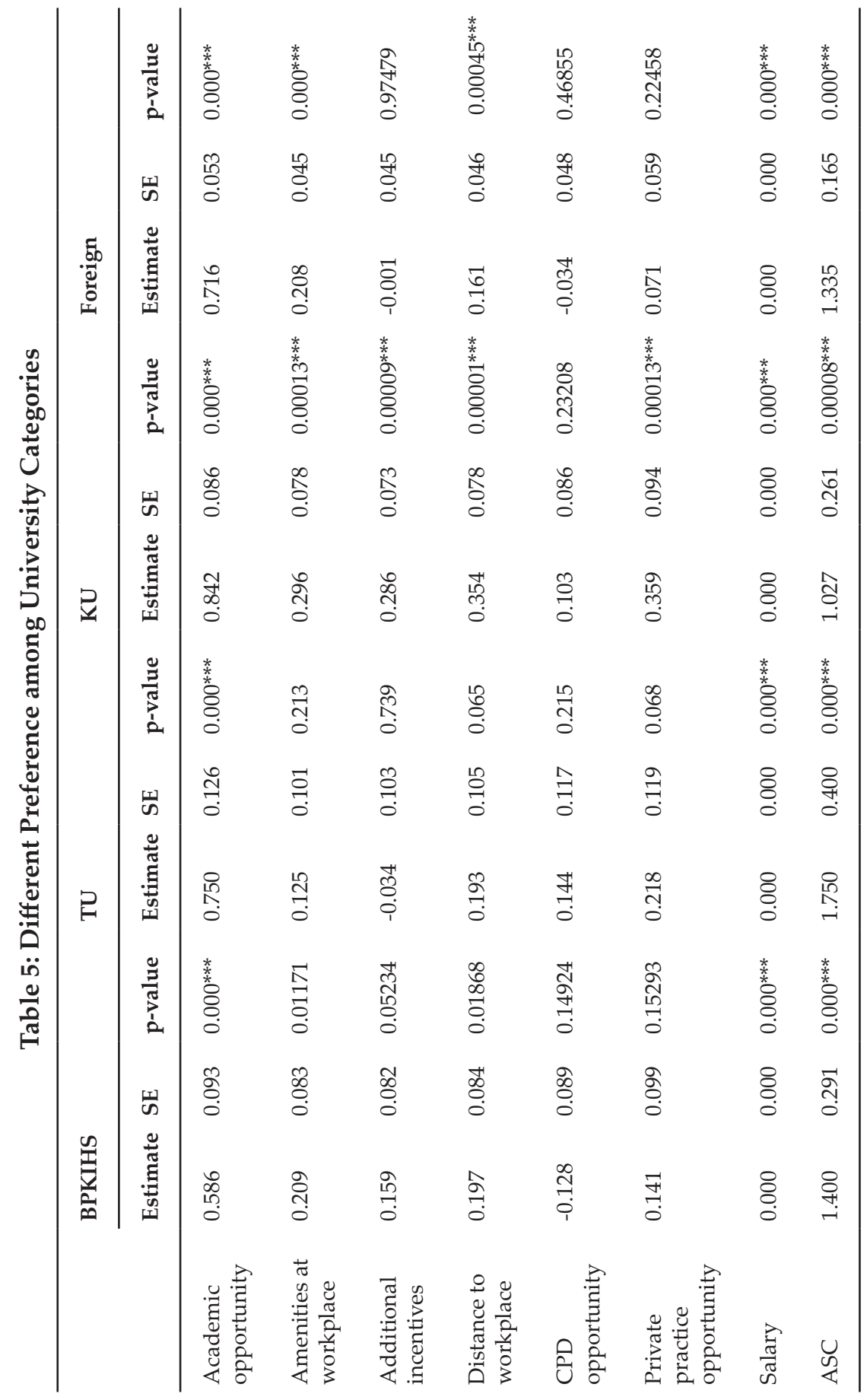


Table 6: Different Preference between Location Categories

\begin{tabular}{lllllll}
\hline & \multicolumn{3}{l}{ Outside Kathmandu valley } & \multicolumn{2}{l}{ Kathmandu valley } \\
\cline { 2 - 7 } & Estimate & SE & p-value & Estimate & SE & p-value \\
\hline Academic opportunity & 0.739 & 0.047 & $0.000^{* * *}$ & 0.611 & 0.061 & $0.000^{* * *}$ \\
Amenities at workplace & 0.254 & 0.041 & $0.000^{* * *}$ & 0.128 & 0.052 & 0.01366 \\
Additional incentives & 0.089 & 0.041 & 0.02752 & 0.098 & 0.052 & 0.05702 \\
Distance to workplace & 0.185 & 0.041 & $0.00001^{* * *}$ & 0.224 & 0.055 & $0.00004^{* * *}$ \\
CPD opportunity & -0.002 & 0.044 & 0.95557 & 0.010 & 0.056 & 0.86313 \\
Private practice & 0.084 & 0.048 & 0.07627 & 0.158 & 0.076 & 0.03713 \\
opportunity & & & & & & \\
Salary & 0.000 & 0.000 & $0.000^{* * *}$ & 0.000 & 0.000 & $0.000^{* * *}$ \\
ASC & 1.533 & 0.149 & $0.000^{* * *}$ & 0.772 & 0.198 & $0.0001^{* * *}$ \\
\hline
\end{tabular}

Monitory valuation of attributes

As per the analysis of monitory value of job attributes, the job seeker i.e. the prospective dentist would be willing to accept the job even with the reduction of Rs 11,996.84 per month for the opportunity of post-graduate education. Likewise, the dentists would be willing to accept the job with the reduction of Rs 3,543.95 per month for good amenities at workplace. A compensation of Rs 3,399.01 would be required for dentists working far away from home. Similarly, with the compensation of Rs 1829.97 and Rs 1568.35 per month, the dentists would be willing to accept the job even if they are not given private practice opportunities and additional incentives respectively. (Table 7).

Table 7: Monetary Value of Job Attributes

\begin{tabular}{ll}
\hline Job attribute & Monetary value (In NRs) \\
\hline Educational opportunity & 11996.84 \\
Amenities at workplace & 3543.95 \\
Distance to workplace & 3399.01 \\
Private practice opportunity & 1829.97 \\
Additional incentives & 1568.35 \\
CPD opportunity & -37.74 \\
\hline
\end{tabular}


Table 8 depicts the monetary value of job attributes, that is, willingness to pay estimates for job seekers comparing the respondents from the Kathmandu valley and outside the Kathmandu valley.

Table 8: Comparison of Monetary Value of Job Attributes between Locations

\begin{tabular}{lcccccccc}
\hline & \multicolumn{7}{c}{ Outside Kathmandu valley } & \multicolumn{7}{c}{ Kathmandu valley } \\
\cline { 2 - 8 } & Estimate & SE & $\mathbf{9 5 \%}$ CI-L & $\mathbf{9 5 \%}$ CI-U & Estimate & SE & $\mathbf{9 5 \% ~ C I - L ~}$ & $\mathbf{9 5 \%}$ CI-U \\
\hline $\begin{array}{l}\text { Academic } \\
\text { opportunity }\end{array}$ & 12673.81 & 796.904 & 11111.874 & 14235.73 & 10727.2 & 993.513 & 8779.912 & 12674.483 \\
$\begin{array}{l}\text { Amenities at } \\
\text { Job }\end{array}$ & 4352.85 & 694.775 & 2991.087 & 5714.606 & 2241.74 & 894.693 & 488.143 & 3995.338 \\
$\begin{array}{l}\text { Additional } \\
\text { incentives }\end{array}$ & 1534.58 & 686.381 & 189.274 & 2879.888 & 1727.23 & 899.749 & -36.231 & 3490.784 \\
$\begin{array}{l}\text { Distance to } \\
\text { workplace }\end{array}$ & 3174.624 & 678.028 & 1845.690 & 4503.559 & 3925.79 & 925.503 & 2111.804 & 5739.775 \\
$\begin{array}{l}\text { CPD } \\
\text { opportunity }\end{array}$ & -41.78 & 750.281 & -1512.326 & 1428.775 & 169.92 & 983.078 & -1756.912 & 2096.754 \\
$\begin{array}{l}\text { Private } \\
\text { practice } \\
\text { opportunity }\end{array}$ & 1445.12 & 815.824 & -153.899 & 3044.130 & 2771.96 & 1321.424 & 181.971 & 5361.953 \\
\hline
\end{tabular}

According to the study, the job seekers from the Kathmandu valley will have to accept the job at the compensation of Rs 10,727.2 per month for the opportunity of PG education; while the job seekers from outside the Kathmandu valley will have to accept the job at the compensation of Rs 12673.81 per month for the same purpose.

\section{DISCUSSION}

While choosing the subjects for prospective dentists' preference for job attributes, fresh graduates and senior level dental students were chosen so that the aspirations of future professionals are represented and there would not be any bias from the respondents who are already settled in job. The subjects of the present study represent the respondents from all three universities producing dental graduates in Nepal. The respondent ratios among gender groups (male and female) and study categories (scholarship and self-finance) are appropriately represented in the sample as per their true proportions.

Discrete choice experiment was chosen for the present study as it is commonly used instrument in health economics, addressing a wide range of policy recommendations. 
So far no study has been conducted for the job preferences in dental health sector in Nepal. The outcome of the study could be useful in formulation of dentists' job opportunities and retention strategies of dental health manpower in desired rural locations. The study has been designed in Nepalese context, with the attributes of job preferences and their levels determined in consultation with the dental professionals, researchers and policy makers.

Based on the key reviews, focus was given to the determination of attributes and their level, experimental design, estimation procedures, and validity of responses. Consideration was also given to how DCEs are applied and analyzed (De BekkerGrob, 2010). The technique is an attribute-based measure of benefit, based on the assumptions that, health-care interventions, services or policies, can be described by their attributes and, that an individual's valuation depends upon the levels of these attributes (Ryan et al., 2008).

Among all respondents, the preference of job attributes while choosing the job choice sets are depicted in Table 1. All the coefficients except for CPD have positive sign, and are statistically significant which means that the attributes have an impact on the probability of choosing job alternative. In our context, a positive sign implies that the attribute has a positive impact on the take-up of a given job; a negative coefficient implies the opposite. For example, coefficient for educational opportunity is positive (0.684) and is statistically significant; which means that having educational opportunity after the job increases the utility of job. Similarly, 'physical amenities at workplace' also increases the utility of job. Most coefficients in the given table have the expected signs. The respondents preferring a job with higher salaries trade-off the possibility of further education to no further education. The job seekers prefer a job where sufficient equipment is provided to one without good amenities, and a job that offers private practice opportunity to one that does not. The coefficients for the CPD were insignificant for which there could be two reasons: either the researchers were unable to estimate the coefficients efficiently with the model used, or there is too much heterogeneity in the preferences for these attributes.

While analysing the job preferences of prospective dentists, models were main effects, no interaction terms were included. All attribute variables were specified as having a random component except for salary, CPD and private practice opportunity, which were specified as fixed in all models. While random specifications of salary may improve model fit, a fixed coefficient ensures that the estimate of salary utility has the right sign and is preferred for calculation and interpretation of willingness to pay, as it avoids possible problems with dividing distributions. The rest attributes do not have a significant standard deviation parameter. Therefore only those attributes with 
significant standard deviation parameters were included in random specification. The constant variable was also specified as fixed.

Furthermore, all attribute variables were effect coded except for salary, which was specified as continuous in all models. All model coefficients were assumed to be normally distributed.

The results were mainly average across the total respondents. However, we also explored a wide variety of heterogeneity in preferences across the respondents' background characteristics. Female preferred lower level of salaries, preferred the job that has CPD opportunities, less preferred the jobs that provides educational opportunity compared to their male counterpart. Similarly, females get relatively less utility in selecting opt-out alternative compared to males (Table 3).

Heterogeneity was also observed across the study type: scholarship and self-finance. Scholarship students choose the opt-out alternative which is indicated by the positive coefficients (Table 3). Heterogeneity was also noticed across the type of university the students are educated from. TU students preferred the job that offers high salaries, while the students from KU preferred the job which offer additional incentives and are nearer to the work place. Students from BP less preferred the job attributes like educational opportunities and higher salary (Table 5).

Lastly, we also observed heterogeneity across the place of origin of the students. Students from Kathmandu valley are less likely to choose opt-out alternative compared to their counterpart. Similarly, they also showed relatively less preference for the job having better physical amenities (Table 8).

Within the context of human resource issues, inclusion of a price proxy (such as salary) allows the researcher to estimate the monetary value of attributes of job, i.e. how much salary a respondent would be willing to give up to have an improvement in other aspects of the job. This can be estimated as the ratio of the value of the coefficient of interest to the negative of the cost attribute. For example, the increment of monthly salary that the job seekers are willing to sacrifice to receive academic opportunity is equivalent to Rs.11996.85. This amount accounts to $27.3 \%$ of the mean expected salary of the respondents. The cumulative incremental amount that would be collected during the job period could contribute to the cost of future education of the aspiring dentists that would surely benefit both the employee and the employer. 


\section{CONCLUSION}

The preferences of job characteristic of Nepalese prospective dentists are: academic opportunity, distance to workplace, private practice opportunity, amenities at workplace, additional incentives, and salary. But the CPD was not considered by the respondents while choosing the job attributes. Job characteristics like education opportunity and amenities at workplace should be given prime importance in creating job opportunities for dentists. The offering of preferred job attributes could be helpful in retaining the dental professionals in rural areas. The monetary values of job attributes could be a profound indicator while formulating the job opportunity and determining minimum tariff of the job.

\section{ACKNOWLEDGEMENT}

The authors would like to thank Dr. Shiva Raj Adhikari, Patan Multiple Campus, Tribhuvan University, for mentoring and guiding the research project; and Institute of Nepal Environment and Health Development (INEHD) and GIZ-Health Support Program for supporting and funding the research project.

\section{References}

Anderson, S.P., Palma, A.De, \& Thisse, J.-F.(1992). Discrete choice theory of product differentiation. Cambridge: MIT Press.

Bekker-Grob, E. W.De., Ryan, M., \& Gerard, K. (2010). Discrete choice experiments in health economics: A review of the literature. Health Economics, 21,145172(2012). Published online in Wiley Online Library (wileyonlinelibrary.com.). doi:10.1002/hec.1697.

Colombet, P., Bourgeois, D., \& Vandeputte, D. (1996). Needs, demands and manpower balance. Dentist/Population. International Dental Journal, 46,543-547.

Crocombe, L., Barnett, T., \&Hoang, H. (2012). Project A: Dental practitioners: Rural work movements. Australia: Centre for Rural Health.

Dixit, S. (2009). Dental manpower status in Nepal (Editorial). Journal of Nepal Dental Association, 10 (1), 1-2.

Gallego, G., Dew, A., Lincoln, M., Bundy, A., Chedid, R. J., Bulkeley, K., Brentnall, J., \& Veitch, C. (2015). Should I stay or should I go? Exploring the job preferences of allied health professionals working with people with disability in rural Australia. Human Resources for Health, 13:53.doi:10.1186/s12960-015-0047-x

Kjær, T.(2005). A review of the discrete choice experiment-with emphasis on its application in health care.(Health Economics Papers 2005:1).University of South Denmark. 
Koopmanschap, M.A., Stolk, E.A., \& Koolman, X. (2010). Dear policy maker: Have you made up your mind? A discrete choice experiment among policy makers and other health professionals. International Journal of Technology Assessment in Health Care, 26(2), 198-204. doi: 10.1017/S0266462310000048

Lancaster, K. J. (1966). A new approach to consumer theory. Journal of Political Economy, 74, 132-157.

Louviere, J.J., Hensher, D.A., \& Swait, J.D. (2000). Stated choice methods: Analysis and applications. Cambridge: Cambridge University Press.

McFadden, D. (1984). Econometric analysis of qualitative response models. In Z. Griliches \& M.D. Intriligator (Eds.), Handbook of econometrics II, (pp.1395-1457). Amsterdam: Elsevier Science.

MHP/GON.(2010). National health sector program II 2010-2015. Kathmandu: Ministry of Health \& Population, Government of Nepal.

MHP/GON. (2014). National oral health policy-Nepal 2014. Kathmandu: Ministry of Health \& Population, Government of Nepal.

NMC. (2013). List of the doctors registered in NMC (1961-23 ${ }^{\text {rd }}$ July, 2013). Kathmandu: Nepal Medical Council.

Paudel, K.R., \& Sharma, M. (2014). Pharmacology curriculum and career option in dental and basic medical sciences: Graduating dental students' perspective under Kathmandu University in Nepal. Asian Journal of Medical Sciences, 5 (2), 106-112. doi: http://dx.doi.org/10.3126/ajms.v5i2.8645

Ryan, H., \& Gerad, K. (2003). Using DCE to value health care programs: Current practice and future research reflections. Applied Health Economics \& Health Policy,2(1), 55-64.

Ryan, M., Bate, A., Eastmond, C. J., \& Ludbrook, A. (2001). Use of discrete choice experiments to elicit preferences. Quality in Health Care, 10 (Suppl I), i55-i60.

Ryan, M., Gerard, K., Amaya-Amaya, M. (Eds.). (2008). Using discrete choice experiments to value health and health care. The Netherlands: Springer.

Santos, B.F. dos, Nicolau, B., Muller, K., Bedos, C., \& Zuanon, A.C. C. (2013). Brazilian dental students' intentions and motivations towards their professional career. Journal of Dental Education, 77, 337-344.

Sapkota, B.P., \& Amatya, A. (2013). Intended location of future career practice among graduating medical students: Perspective from social cognitive career theory in Nepal. Journal of Nepal Health Research Council, 11(25), 229-234. 
Shrestha, R.M. (2015). Situation analysis of human resource in dental health. INEHD (unpublished report).

Shrestha, S., \& Maharjan, S. (2008). Facts about Nepalese dentists.Dentistry Nepal, 3(1), 31.

Train, K.E.(2003). Discretechoice methods with simulation. ( $2^{\text {nd }}$ ed.). Cambridge: Cambridge University Press.

Ubach, C., Scott, A., French, F., Awramenko, M., \& Needham, G. (2003). What do hospital consultants value about their jobs? A discrete choice experiment. British Medical Journal, 326, 1432

WHO. (2006).World health report 2006: Working together for health (on line). Accessed fromhttp://www.who.int/whr/2006/en/

WHO.(2012).User guide with case studies. How to conduct a DCE for health workforce recruitment and retention in remote and rural areas. Author 